\title{
Fashion Representation of Henan Opera Art in Two- Dimensional Animation
}

\author{
Lina Shang \\ Huanghe Science and Technology College \\ Zhengzhou, China, 450063 \\ e-mail: 461671549@qq.com
}

\begin{abstract}
The combination of the animation short film and Chinese opera is like the collision of traditional and modern, which made people feel fresh and contradictory at the same time. This combination has aroused the interests of people from the time it started out, and the later publicity is very smooth like a duck to water. The combination of elements of Chinese opera and other folk arts with the creation of the animation short film make it rich of strong national character, and distinct sense of the times. In order to increase the Central Plains cultural characteristics in the animation short film, the creation of the animation short film not only integrate the visual elements of Henan opera, but also blend the Central Plains traditional folk art elements into the creation. The combination of the elements of Henan opera and traditional folk art forms have represented in the two-dimensional animation in a brand-new way, which is also the breakthrough and innovation of the two in the two-dimensional animation.
\end{abstract}

Keywords-Henan opera art; two-dimensional animation; fashion; representation

\section{INTRODUCTION}

Henan opera art has very strong Henan local characteristics. Its firmness and straightforwardness, and outburst of enthusiasm all display the unsophisticated folkways of the Central Plains people and the unique local customs and practices of Henan province. Henan opera has formed its unique esthetic characteristics during the development of thousands of years. However, due to the rapid development of modern science and technology, all kinds of contemporary entertainment forms have sprung up continually. The developments of media also have changed the ways and approaches of people to appreciate traditional art. Especially the traditional opera art has been forgotten by the young people, caused the traditional opera art faced with a recession of inheritance. In order to carry forward the folk art and inherit the opera art, the animation opera, an art form with the glamour of traditional Chinese art, emerged at the right moment.

"The generation of each artistic form will inevitably experience the development process from practical to aesthetic on the premise of labor, which seems to be the route that each artistic form must take" ${ }^{[1]}$. The combination

${ }^{[1]}$ Gao Lin. On the Inheritance and Extension of Henan Opera in the Opera of the animation short film and Chinese opera is like the collision of traditional and modern, which made people feel fresh and contradictory at the same time. This combination has aroused the interests of people from the time it started out, and the later publicity is very smooth like a duck to water. In the integration of the visual elements of traditional opera in the creation of the animation short film, whether to preserve the connotation form or give up the restrictions of rules to rediscover the visual elements of the opera is the shining point and difficulty for the blending of traditional elements with modern design, which is also the focus of attention for animation creation.

\section{HENAN OPERA ELEMENTS INCORPORATE WITH TRADITIONAL FOLK ART}

In the creation of animation short film, the single reference of one visual element would make the role designed seemed thin, while the animation combined with different elements would be full. Chinese traditional folk arts are rich in type and various in form. Especially in the Central Plains area, besides the traditional opera, there are many other forms of traditional folk arts like wooden New Year pictures in Zhuxian town, paper cutting, shadow puppet, Kaifeng embroidery, and Chinese wheat straw picture, etc. The combination of the elements of Henan opera and traditional folk art forms have represented in the twodimensional animation in a brand-new way, which is also the breakthrough and innovation of the two in the twodimensional animation.

\section{A. Shadow Puppet}

Shadow puppetry was originated form the Warring States Period, prospered in the Han Dynasty and reached its peak in the Song Dynasty. In Yuan Dynasty, shadow puppetry spread to Western Asia and Europe. Shadow puppetry has a long and honored history indeed. Due to the vast territory of China, shadow puppetry in different places has their own characteristics. Henan shadow puppetry was mainly distributed in the south and west of the province. Tongbai shadow puppetry is the major form, which puppet has a strong sense of unity and bright tone. The artists dared to be bold and exaggerated, as well as to sacrifice details.

Animation [J]. Beijing: Movie Reviews,2009. 
The character modeling of shadow puppetry has very simple outer outline, but very complicated and delicate inner carving and painting, and very intensive engraved holes. This kind of design can be called "simple outer but complicate inner part", "using simple to unify the complicated", which is rich and unified.

Besides the examples of the combination of traditional opera and shadow puppet elements in the early Chinese animation, Henan opera animation has also made references form these elements. For example, Henan opera animation "Secrets of Songshan Mountain", created by the first class creative team of CCTV Dream Channel, contains the fresh elements of shadow play animation, Henan local dialect, Henan opera and three-dimensional animation, etc., which attracted many arts and entertainment programs fans.

It took one year to create "Secrets of Songshan Mountain", includes 5 episodes. The main creation line is Henan Songshan mountain culture, fetched materials from history and myths, celebrity stories, culture and so on from the ancient times to the Ming and Qing periods. The cartoon describes the classical historical and cultural stories including emperor fighting, legend of Kai Mother Stone, Kublai Khan built the star observation, legend of the Tang Dynasty palace revolt, academy of Song Dynasty, Shaolin Temple and so on. It integrates the most distinct elements of the Central Plains and China by architecture archives, geological founding, religious code, myths and legends and historical moments, presented in a brand new way. Compared with the documentary film in the past, this cartoon has very distinctive features. First, it uses the distinct regional culture codes of native language and traditional Henan opera to display the charm of Central Plains' humanity and art. Second, it makes full use of the twodimensional and three dimensional animation technologies. For example, shadow puppetry takes it debut on the screen in the form of animation, performing scenes of historical events and folk legends. Restore ancient architectural complex of Songshang Mountain by the three-dimensional digital technology, made people be personally on the scene to experience the essence of Henan Songshang history. Third, it has vivid, humorous and wise language, which not only make the serious history easy to be understood, but also lead people to endless aftertastes by the smart and sharp remarks.

\section{B. Paper Cutting}

Paper cutting is one of the oldest folk art of Chinese nation, with special art charm. Henan paper cutting with the highest achievement is in Western Henan area. Western Henan paper cutting includes the bronze ornamentation features in Shang and Zhou Dynasties, as well as the Han dynasty stone portraits in Nanyang, New Year pictures of Zhuxian town, and statues of Longmen Grottoes in Northern Wei Dynasty. It is simple and rough, powerful and grand. What merits a special note is that the production and life style and concept reflected by Western Henan paper cutting are the inheritance of thousands of years' agriculture civilization, gathered the connotation and characteristics of the folk culture of Chinese nation. Animation "Dingjun Mountain", produced by the Central Drama Academy, employed the modeling elements of paper cutting and shadow puppet to represent the classic part of the opera. In the scene design, trees are made according to Chinese paper cutting, and character modeling is indeed learned from shadow puppet. Because paper cutting animation is very hard, Professor Yu Jinhui of Zhejiang University has pointed out that Chinese traditional animation has very high production cost and low efficiency. "The mascot animation of 2008 Olympic Games was made by paper cutting, directed by Professor Lu Shengzhang. The 3 minutes cartoon took four months work by Professor Lu's daughter and some postgraduate students, whose hands were worn out at last." The prevailing animated series with several hundreds episodes cannot bear the cost of hand made paper cutting. "Therefore, it is a pity that this method has not been integrated in Henan opera cartoon." [1]

\section{New Year Pictures}

According to the record of "Dreamlike Glory of the Eastern Capital", wooden New Year pictures were very thriving in Bianjing area in the Northern Song Dynasty. On festival days, street markets all sold New Year pictures painted with kitchen god and door god. During the middle Ming Dynasty and the early Qing Dynasty, the number of workshops producing wooden New Year pictures in Zhuxian town was over 300 , specialized in producing door god, red paper and so on. The style of the picture is bold and simple, with full composition, bright colors and exaggerated shapes. There are different kinds including martial door god, literary door god, statue of god, painting of the characters in opera, and hanging ornament, etc.. The martial door gods has general, martial god of wealth, warrior and so on. The literary door gods has the type of blessing god, boy and exorcise evil spirits. The wooden New Year pictures in Zhuxian town have five features: bold lines, coarse alternating with fine lines; exaggerated images with big head but small body; delicate structure with bilateral symmetry, bright colors with contrasts; and various shapes of door god, serious and dignified.

Animated cartoon "Wooden New Year Pictures", produced by Zhengzhou Visual Film Co., integrated the wooden New Year pictures with Henan opera. In the creation of the cartoon, Henan opera was mainly represented in the behaviors and music for voices, and the modeling was employed form the wooden New Year pictures in Zhuxian town.

These excellent animation short films are the fine representatives of traditional opera cartoons in recent years, displayed the elements of traditional opera incisively and vividly not matter in visual effect or in performance mode. There works combined the elements of traditional opera with other folk arts in the creation, made them rich of strong national character, and distinct sense of the times. In order to make the animated short film has distinct traditional Central Plains' cultural features, the creation of the film not only has

[1] Quote from Sohu. Traditional Cartoon: How to Rise in Reminiscence and Innovation. Website: http://it.sohu.com/20070522 / n250156502. Shtml 
the visual features of Henan opera, but also can integrate other traditional Central Plains' folk arts elements into the creation.

\section{COMBInE ElEMENTS OF HENAN OPERA WITH THREE DIMENSIONAL TECHNOLOGY}

In recent years, due to the global business and art successes of 3D animations produced by corporations like Pixar and DreamWorks, etc., the employment of computer technology in the creation of animation cartoon was especially popular. Although this is an era of CG, the cartoon film that produced by traditional technology and contained national cultural connotation is the developing trend. "The beginning of "New Guideways of Mountains and Seas" (Pic.2-1), Qiu Anxiong's water-and-ink animation, simulated the miniature of civilization in a subtle humorous way. In Shanghai Photography Biennale, 2006, on the three big screens connect together like a spreading scroll, this animation played in a continuous loop, which have attracted many audiences by the special combination of the high technology and the ancient artistic conception. ${ }^{[2]}$

Henan opera animation "Secrets of Songshan Mountain" was the newly arisen product of the combination with $3 \mathrm{D}$ technology, restored ancient architectural complex of Songshang Mountain by the three-dimensional digital technology, made people be personally on the scene to experience the essence of Henan Songshang history. It employed the intercross fusing of digital technology and traditional opera, derived avant-garde but dignified traditional opera animation, which has strategic significance for the inheritance and protection of traditional opera cultural heritage.

\section{DRAW LESSONS FROM FOREIGN ANIMATION TO REALIZE DIVERSIFIED DEVELOPMENT}

"We can still stick to the creation of cartoon series with national style, but the premise of the perseverance is the correct understanding and exact grasp of the national style of the cartoon. We must also realize that there are many ways to success for the creation of cartoon, while the presentation of national style was one of the ways to success that has been experienced. We should actively discover other techniques of expression to share the heavy responsibility of saving Chinese animation. From American Disney animation, we can see that whether it is national and traditional or not, the animation with fine manufacture and excellent story will be popular in the market. From Japanese animation, we can learn that in the employment of national elements, animation should have profound humanistic feelings that could penetrate into our hearts after viewing and make people be lost in thought and reflection. In European animation short film, we can see that the expression methods of animation are various, different media and expressing ways could be used. "Don't be restricted to the 2D painting or 3D computer

${ }^{[2]}$ Southern People Weekly, http://news.sina.com.cn/c/cul/2006-0921/144211069503.shtml, Sep.21, 2006. modeling, and people can produce an animation by iron wire at last"., "[3]

At present, foreign animation industry has realized that the animation cannot only draw materials from their own nation, but also should combine the characteristics of different nations. They have made some experiments on this and achieved good economic benefits. With the increasingly perfecting of the technology and method, they also have the trouble on finding good subjects. Under the trend of global integration, foreign animation industry began to search classical subjects throughout the world to use in their animation creation. Animation films "Kung Fu Panda" and "Mulan" are all the classical subjects of China that have profound Chinese cultural connotation, but how could they receive such huge box office and high ratings on a global scale after the recreation and redesign by the Euramerican animation creators? The fact that Chinese materials developed and promoted by the Euramerican and benefited to Euramerican animation corporations greatly must draw the attention and reflection of Chinese government and the related animation enterprises. Facing the fact that our traditional cultural subjects were frequently planted in the foreign soil, took roots and sprout, and bloomed charming and fragrant flowers, should we need to think of it seriously?

Taking this for a lesson, since they have learned form our classical works, why should not we take their ancient classical stories for reference? Why did we reproduce the familiar classic stories once and once again? There are only differences between nice and unsightly, no nations or borders. A good creative theme will be popular among the audience no matter it is China or foreign. The aim of animation and movie and television is for spreading culture. If Chinese animation aims to have influence on the world stage, it must incorporate global culture. The culture of the world is in the same platform. The using of foreign culture could produce a novel effect on Chinese animation, and thus promote the development of Chinese animation. Therefore, the creative theme of Chinese animation film should absorb the culture of other countries to make it rich and plentiful. It needs diversified development for the animation creative theme. If they only reproduce of the old themes, or toughly bring foreign themes under the creation background of China and cater to the contents of Chinese animation, they will be the stumbling block of Chinese animation development, making which in a more closed state. In conclusion, Chinese animation cannot only draw materials in our own nation.

The main reason of the slow development of Chinese animation industry is that Chinese animation positioned to childish orientation and preaching. Second, the contents of our animation were mainly drawn from historical legends, lacking the innovativeness with the times. In the nationalization progress of Chinese animation, we can absorb and learn from the excellent achievements of Japanese animation. "The development of domestic original animation should begin with Chinese traditional value

$\left.{ }^{[3}\right]$ Chen Yawei. The Reference Significance of Foreign Animation's National Style toward Chinese Animation [M]. China Western Development· Midmonth Edition. 2012.05.57 
conception, pay special attention to the creative thinking and artistic style, and produce our own animation." [4]

To sum up, in order to create animation film with Central Plains' characteristics, we should not only draw lessons from the traditional opera visual elements in the creation, but also learn from other Central Plains' traditional artistic elements and advanced modern computer technology. Thus the animation will have the characteristics of Central Plains, as well as the modern pattern of presentation.

\section{REFERENCES}

[1] Gao Lin. On the Inheritance and Extension of Henan Opera in the Opera Animation [J]. Beijing: Movie Reviews,2009.

[2] Quote from Sohu. Traditional Cartoon: How to Rise in Reminiscence and Innovation. Website: http://it.sohu.com/20070522/ n250156502. Shtml

[3] Southern People Weekly, http://news.sina.com.cn/c/cul/2006-0921/144211069503.shtml, Sep.21, 2006.

${ }^{[4]}$ Ding Hong. Research on the Diversified Development of Aardman Animations and International Animations [D]. Shantou University.2009.76 